\title{
Palatability as an addictive trigger in obesity: a changing paradigm in the past decades
}

\section{Noemi Malandrino* and Esmeralda Capristo}

Institute of Internal Medicine, Catholic University of Rome, Rome, Italy

*Correspondence: noemimalandrino@gmail.com

\section{A commentary on}

Why has the BMI gone up so drastically in the last 35 years?

by Lindberg, M. A., Dementieva, Y., and Cavender, J. (2011). J. Addict. Med. 5, 272-278.

A recent study by Lindberg et al. (2011) in the Journal of Addiction Medicine aimed at answering a specific question, i.e., if some food groups or additives have been more responsible than others in the dramatic increase in body mass index (BMI) during the last decades. This study demonstrated that the additives of fats and sugars in combination, not separately, best predicted increases in BMI accounting for $97 \%$ of the variance in the linear regression analyses. Lindberg et al. (2011) conclude highlighting the importance of palatability as the addictive trigger, as fats and sugars in combination rather than calories per se or particular food groups accounted for the increases in BMI.

The authors of this study have to be commended as they conducted a complex study analyzing archival data related to a 35-year period from the United States Department of Agriculture and the Center for Disease Control (Lindberg et al., 2011). Their results are consistent with the increasing evidence that obesity represents an emerging addictive disorder. In particular, this study clearly points out the importance of palatability as the addictive trigger in obese individuals. These findings based on archival data are consistent with imaging studies showing the importance of food palatability in the neurobiology of obesity. For example, Wang et al. (2009) demonstrated that the reduction in dopamine D2 receptors in obese subjects coupled with the enhanced sensitivity to food palatability could be responsible for making food their most salient reinforcer putting them at risk for compulsive eating and obesity.
Lindberg et al.'s (2011) study provides further convincing evidence that obesity needs to be considered not only a metabolic and endocrine disorder, but also a behavioral and psychiatric disorder. The diagnostic and statistical manual of mental disorders (DSM), for example, is moving toward this direction (e.g., see Volkow and O'Brien, 2007). Just to cite an example (among the many examples that could be mentioned), there is a high comorbidity among addictive disorders, and sweet likers, as compared to sweet dislikers, are at higher risk for developing alcohol-related problems (e.g., Kampov-Polevoy et al., 2003). These findings (reviewed in Leggio et al., 2011) are interesting because not only they identify a specific endophenotype, but also they highlight how sweet preference is strongly linked to another addictive disorder (e.g., alcoholism), further pointing out the addictive properties of a palatable behavior such as a sweet-liking behavior.

The take home message is that there is a crucial need for a more comprehensive management of obese patients. Asking these patients to reduce their food intake is not enough; rather it is important to consider treatment approaches that target palatability as the addictive trigger responsible for the persistence and increased prevalence of obesity. This has been and is still a challenge because of the need for identifying treatment approaches (e.g., pharmacotherapies), which are both safe and effective. Nonetheless, research is moving toward this direction. For example, despite the recent removal of rimonabant, researchers are making efforts to demonstrate the ability of other pharmacotherapies to selectively reduce motivation to obtain highly palatable reinforcers (e.g., CB1 antagonists Droste et al., 2010).

Therefore, consistent with the increasing need for a more personalized medicine (Malandrino and Smith, 2011) it is more and more important to develop a more integrated approach in the management of obese patients, including the need to follow-up these patients by team players coming from different fields (e.g., endocrinology and metabolism, psychiatry, addiction medicine, behavioral medicine).

\section{REFERENCES}

Droste, S. M., Saland, S. K., Schlitter, E. K., and Rodefer, J. S. (2010). AM 251 differentially effects food-maintained responding depending on food palatability. Pharmacol. Biochem. Behav. 95, 443-448.

Kampov-Polevoy, A. B., Ziedonis, D., Steinberg, M. L., Pinsky, I., Krejci, J., Eick, C., Boland, G., Khalitov, E., and Crews, F. T. (2003). Association between sweet preference and paternal history of alcoholism in psychiatric and substance abuse patients. Alcohol. Clin. Exp. Res. 27, 1929-1936.

Leggio, L., Addolorato, G., Cippitelli, A., Jerlhag, E., Kampov-Polevoy, A. B., and Swift, R. M. (2011). Role of feeding-related pathways in alcohol dependence: $\mathrm{A}$ focus on sweet preference, NPY, and ghrelin. Alcohol. Clin. Exp. Res. 35, 194-202.

Lindberg, M. A., Dementieva, Y., and Cavender, J. (2011). Why has the BMI gone up so drastically in the last 35 years? J. Addict. Med. 5, 272-278.

Malandrino, N., and Smith, R. J. (2011). Personalized medicine in diabetes. Clin. Chem. 57, 231-240.

Volkow, N. D., and O’Brien, C. P. (2007). Issues for DSMV: should obesity be included as a brain disorder? Am J. Psychiatry 164, 708-710.

Wang, G. J., Volkow, N. D., Thanos, P. K., and Fowler, J. S. (2009). Imaging of brain dopamine pathways: implications for understanding obesity. J. Addict. Med. 3, 8-18.

Received: 27 December 2011; accepted: 27 December 2011; published online: 10 January 2012.

Citation: Malandrino Nand Capristo E (2012) Palatability as an addictive trigger in obesity: a changing paradigm in the past decades. Front. Psychiatry 2:81. doi: 10.3389/ fpsyt.2011.00081

This article was submitted to Frontiers in Addictive Disorders, a specialty of Frontiers in Psychiatry.

Copyright (C) 2012 Malandrino and Capristo. This is an open-access article distributed under the terms of the Creative Commons Attribution Non Commercial License, which permits non-commercial use, distribution, and reproduction in other forums, provided the original authors and source are credited. 